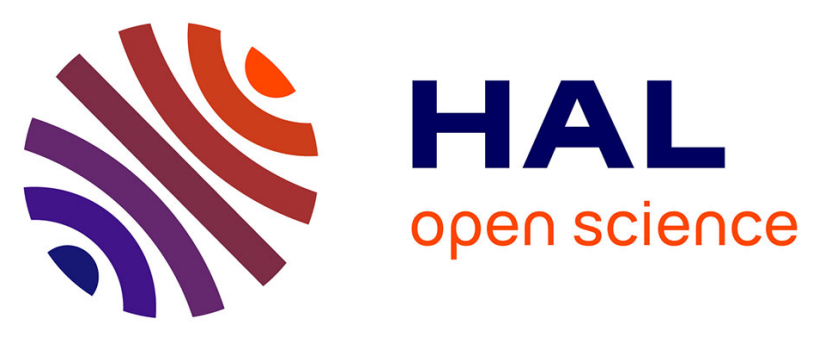

\title{
Influence of size, surface coating and fine chemical composition on the in vitro reactivity and in vivo biodistribution of lipid nanocapsules versus lipid nanoemulsions in cancer models
}

Samuli Hirsjärvi, Sandrine Dufort, Julien Gravier, Isabelle Texier, Qiao Yan, Jérome Bibette, Lucie Sancey, Veronique Josserand, Catherine

Passirani-Malleret, Jean-Pierre Benoit, et al.

\section{- To cite this version:}

Samuli Hirsjärvi, Sandrine Dufort, Julien Gravier, Isabelle Texier, Qiao Yan, et al.. Influence of size, surface coating and fine chemical composition on the in vitro reactivity and in vivo biodistribution of lipid nanocapsules versus lipid nanoemulsions in cancer models. Nanomedicine: Nanotechnology, Biology and Medicine, 2013, 9 (3), pp.375-87. 10.1016/j.nano.2012.08.005 . hal-03180818

\section{HAL Id: hal-03180818 \\ https://univ-angers.hal.science/hal-03180818}

Submitted on 25 Mar 2021

HAL is a multi-disciplinary open access archive for the deposit and dissemination of scientific research documents, whether they are published or not. The documents may come from teaching and research institutions in France or abroad, or from public or private research centers.
L'archive ouverte pluridisciplinaire HAL, est destinée au dépôt et à la diffusion de documents scientifiques de niveau recherche, publiés ou non, émanant des établissements d'enseignement et de recherche français ou étrangers, des laboratoires publics ou privés. 


\title{
Influence of size, surface coating and fine chemical composition on the in vitro reactivity and in vivo biodistribution of lipid nanocapsules versus lipid nanoemulsions in cancer models
}

\author{
Samuli Hirsjärvi, $\mathrm{PhD}^{\mathrm{c}, 1}$, Sandrine Dufort, $\mathrm{PhD}^{\mathrm{a}, \mathrm{b}, 1}$, Julien Gravier, $\mathrm{PhD}^{\mathrm{d}, 1}$, \\ Isabelle Texier, $\mathrm{PhD}^{\mathrm{d}}$, Qiao Yan, $\mathrm{PhD}^{\mathrm{e}}$, Jérome Bibette, $\mathrm{PhD}^{\mathrm{e}}$, Lucie Sancey, $\mathrm{PhD}^{\mathrm{a}, \mathrm{b}}$, \\ Véronique Josserand, $\mathrm{PhD}^{\mathrm{a}, \mathrm{b}}$, Catherine Passirani, $\mathrm{PhD}^{\mathrm{c}}$, \\ Jean-Pierre Benoit, $\mathrm{PhD}^{\mathrm{c}}$, Jean-Luc Coll, $\mathrm{PhD}^{\mathrm{a}, \mathrm{b}, *}$ \\ a INSERM U823, Institut Albert Bonniot, 38706 Grenoble, France \\ ${ }^{\mathrm{b}}$ Université Joseph Fourier, Grenoble, France \\ ${ }^{\mathrm{c}}$ INSERM U646, Angers, France \\ ${ }^{\mathrm{d}}$ CEA, LETI/DTBS, Grenoble, France \\ ${ }^{\mathrm{e}}$ ESPCI, Paris, France \\ Received 20 January 2012; accepted 8 August 2012
}

\begin{abstract}
Lipid nanocapsules (LNCs) and lipid nanoemulsions (LNEs) are biomimetic synthetic nanocarriers. Their in vitro and in vivo performance was evaluated as a function of their size $(25,50$ and $100 \mathrm{~nm})$ and the surface PEG chain length. Analysis methods included complement activation test, particle uptake in macrophage and HEK293(B3) cells and biodistribution studies with tumor-grafted mice by fluorescence imaging. A particular attention was paid to keep the concentration of each nanocarrier and to the amount of fluorescent dye in comparable conditions between the in vitro and in vivo studies. Under these conditions, no significant differences were found among the three tested particle sizes and the two nanocarrier types. Longer PEG chains on the LNE surface provided better stealth properties, whereas PEG modification on the LNC formulations inhibited the production of stable nanocarriers. Passive accumulation of LNCs and LNEs in different tumor types depended on the degree of tumor vascularization.
\end{abstract}

From the Clinical Editor: This study of lipid nanocapsules and lipid nanoemulsions compares their vitro and in vivo performance as a function of size and surface PEG chain length, demonstrating no significant difference among the tested particle sizes. Longer PEG chains on the LNE surface provided better stealth properties, whereas PEG modification on the LNC formulations inhibited the production of stable nanocarriers. (C) 2013 Elsevier Inc. All rights reserved.

Key words: Biocompatible materials; Biodistribution; Lipid nanocarriers; Nanoparticles; Near-infrared optical imaging

Sources of support for research: This work was supported by the Institut National de la Santé et de la Recherche Médicale (INSERM), the University Joseph Fourier Grenoble 1, the Commissariat à l'Energie Atomique et aux Energies Alternatives (CEA), the cancéropole CLARA, the INCA (Institut National for Cancer), and the French National Research Agency (ANR) in the frame of its programme in Nanosciences and Nanotechnologies (CALIF project no. ANR-08-NANO-006). S. Hirsjärvi acknowledges Academy of Finland for funding.

*Corresponding author: INSERM-UJF U823, Institut Albert Bonniot, 38706 Grenoble, France.

E-mail address: Jean-Luc.Coll@ujf-grenoble.fr (J.-L. Coll).

1 These three authors contributed equally.
Lipid nanocapsules (LNCs) $)^{1-3}$ and lipid nanoemulsions $(\mathrm{LNEs})^{4-7}$ are two types of synthetic particles, with tunable diameters ranging between 25 and $100 \mathrm{~nm}$ that offer versatility for the delivery of drugs, ${ }^{8-12}$ DNA, ${ }^{13,14}$ radiotherapeutics ${ }^{15-17}$ and imaging agents. ${ }^{18,19}$

They are spherical, made of biocompatible materials, and exhibit good dispersion stability. Their surfaces contain polyethylene glycol (PEG) chains that provide stealth properties. They are both produced in solvent-free conditions, using easily scalable processes: LNCs are prepared by a low-energy phase inversion temperature method, while LNEs are formed using homogenization by 
A

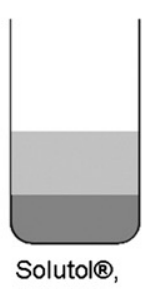

Lipoid@,

Labrafac®,

$\mathrm{NaCl}$, water
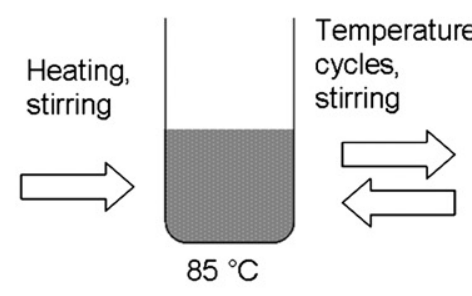

$85^{\circ} \mathrm{C}$

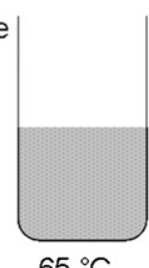

$65^{\circ} \mathrm{C}$

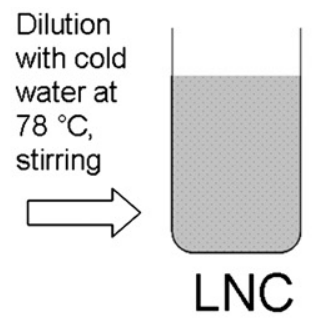

Dilution

stirring

B

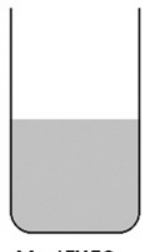

Myrj ${ }^{\mathrm{TM}} 53$,

$\mathrm{NaCl}$, water
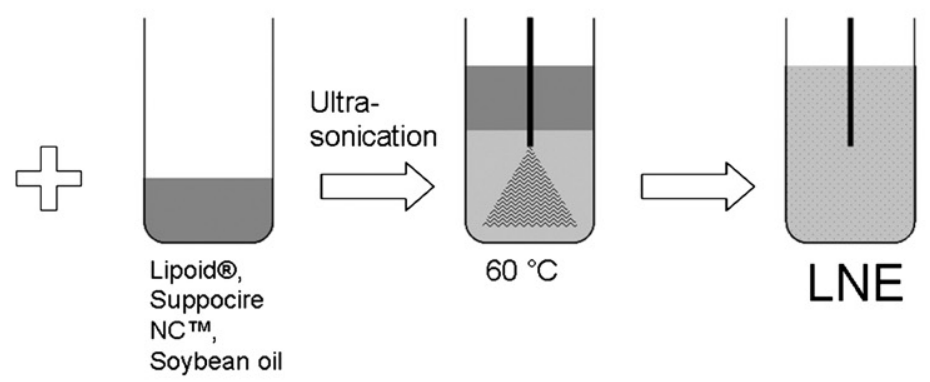

NC ${ }^{\mathrm{TM}}$,

$60^{\circ} \mathrm{C}$

LNC

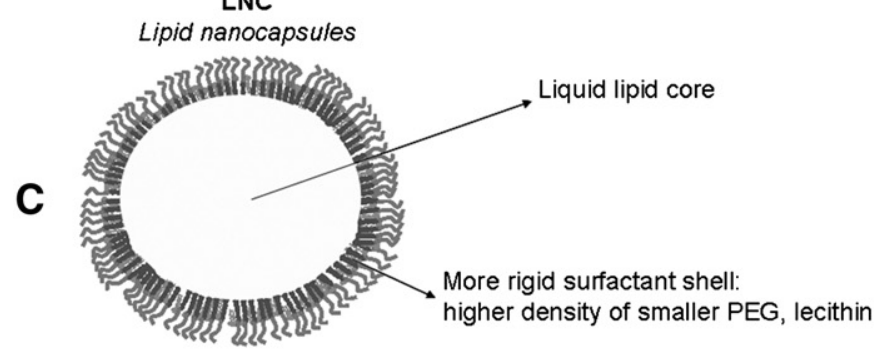

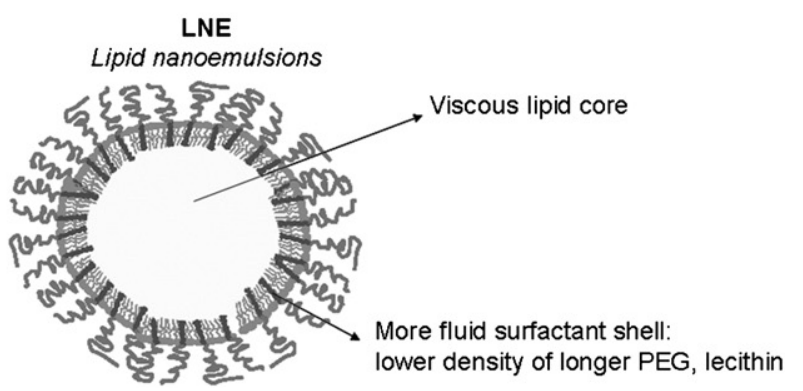

Figure 1. Schematic presentation of the LNC (A) and LNE (B) preparation methods, and the structures of LNCs and LNEs (C). The major difference between LNCs and LNEs is coming from the type of energy provided for their formation: heating is used for LNCs and sonication for LNEs. LNCs are expected to be more rigid than LNEs.

ultrasonication (Figure 1). Both LNCs and LNEs can be characterized as hybrids of micelles (with a swollen lipid core) and polymer nanocapsules (shell consisting of a mixture of lecithin and a PEGylated surfactant). However, although their structures are similar, they present subtle differences (Supplementary Figure 1, available online at http://www.nanomedjournal.com). LNCs have a fairly rigid shell that stably anchors the PEGylated surfactant in the lipid core. In comparison, the LNE shell surfactant is more mobile. The particle's stability is ensured by the low water solubility of the lipid core and the use of a complex lipid/surfactant structure that increases the particle's entropic stability. ${ }^{6}$ The length of the PEG chains can also be modified to decrease protein adsorption and increase the stealth properties of nanocarriers because PEG chain length is correlated with protein adsorption and stealth characteristics. $^{20}$

Their size ranging from 25 to $100 \mathrm{~nm}$ favors their accumulation in tumors via the enhanced permeability and retention (EPR) effect. ${ }^{21}$ LNCs and LNEs are thus powerful tools for studying how physicochemical variations can influence nanocarrier biodistribution in vivo.
In this study, we evaluated the pharmacokinetics and organ/ tissue distribution of fluorescent LNCs and LNEs. The effects of nanocarrier diameter $(25,50$ and $100 \mathrm{~nm})$ and surface modification by different PEG chains were assessed. The following methods were used for in vitro evaluation: the $\mathrm{CH} 50$ complement activation test and particle uptake studies using macrophage (THP-1) and HEK293( $\beta 3$ ) cells. The HEK293( $\beta 3$ ) cells are a human embryonic kidney cell line that overexpresses $\alpha_{\mathrm{v}} \beta_{3}$ integrins, making them a good model for nanocarriers grafted with RGD-type targeting peptides. ${ }^{7,22}$ In vivo biodistribution studies were performed with mice with HEK293 tumors, in addition to three other tumor models that exhibited various degrees of vascularization.

\section{Methods}

\section{Materials}

Solutol HS15 (PEG 660 12-hydroxystearate) was a gift from BASF (Ludwigshafen, Germany) and stearate of PEG 1500 (DUB S PEG 30 S) was donated by Stéarinerie Dubois (Boulogne 
Billancourt, France). Myr 53 (PEG 40 stearate, 1980 Da), Myrj 49P (PEG 20 stearate, 800 Da), and Super Refined Soybean Oil were obtained from Croda Uniquema (Chocques, France). Labrafac WL 1349 (caprylic/capric acid triglycerides) and Suppocire NC were bought from Gattefossé S.A. (Saint-Priest, France), and Lipoid S75-3 (lecithin with more than $75 \%$ phosphatidylcholine) was bought from Lipoid $\mathrm{GmbH}$ (Ludwigshafen, Germany). MilliQ185 water (Waters, Saint-Quentin-enYveline, France) was used in all experiments. The fluorescent dye, DiD (1, $1^{\prime}$-dioctadecyl-3,3,3', $3^{\prime}$-tetramethylindodicarbocyanine perchlorate), was obtained from Invitrogen (Cergy Pontoise, France). All other reagents were of analytical grade.

\section{Preparation of LNCS and LNES}

LNCs were prepared according to the phase inversion temperature method described by Heurtault et $\mathrm{al}^{1}$ (Figure 1). Briefly, a mixture of Solutol (or PEG 1500), Lipoid, Labrafac, $\mathrm{NaCl}\left(5 \%\right.$ in water) and water was heated to $85^{\circ} \mathrm{C}\left(95^{\circ} \mathrm{C}\right.$ with the PEG 1500 formulation) at a rate of $5{ }^{\circ} \mathrm{C} / \mathrm{min}$, followed by cooling at the same rate to $65^{\circ} \mathrm{C}$. This cycle was repeated twice. When the mixture reached $78{ }^{\circ} \mathrm{C}\left(85{ }^{\circ} \mathrm{C}\right.$ with the SPEG 1500 formulation) during the phase inversion zone of the last cooling cycle, the system was diluted with cold $\left(0{ }^{\circ} \mathrm{C}\right)$ water, leading to formation of stable LNCs. Fluorescent dye (DiD), dissolved in acetone, was added to the formulation vial, followed by evaporation of the acetone before adding the LNC components. The final local dye concentration in the nanocarriers was approximately $1.2 \mathrm{mM}$. The LNC dispersions were filtered through $0.22 \mu \mathrm{m}$ filters (Minisart High-Flow, Sartorius Stedim Biotech, Goettingen, Germany).

LNEs were prepared as described by Goutayer et $\mathrm{al}^{4}$ (Figure 1). $80 \mu \mathrm{L}$ of $10 \mathrm{mM}$ dye solution in $\mathrm{CH}_{2} \mathrm{Cl}_{2}$ was poured into a $5 \mathrm{ml}$ vial, for a final dye concentration in the nanocarriers of about $1.2 \mathrm{mM}$. The solvent was evaporated under vacuum before the oil premix (Soybean oil, Suppocire NC and Lipoid) was added. Myrj 53 or Myrj 49P was dissolved in $154 \mathrm{mM} \mathrm{NaCl}$ aqueous solution and added to the oily premix. The mixture was placed in a $60{ }^{\circ} \mathrm{C}$ water bath and sonicated for 5 min using a VCX750 Ultrasonic processor (power output $190 \mathrm{~W}$, probe diameter $3 \mathrm{~mm}$, Sonics, Newtown). LNEs were dialyzed overnight at room temperature against an aqueous buffer ( $\mathrm{M}_{\mathrm{W}} \mathrm{CO} 12-14 \mathrm{kDa}$ membranes, ZelluTrans) and filtered through $0.22 \mu \mathrm{m}$ filters (Minisart High-Flow, Sartorius Stedim Biotech, Goettingen, Germany).

The size of both nanocarriers could be adjusted by changing the proportions of the components (see supplementary Table 1). For a given PEG length, three sizes were formulated: $25 \mathrm{~nm}$, $50 \mathrm{~nm}$, and $100 \mathrm{~nm}$. Another PEG length (1500 Da for LNC; 880 Da for LNE) was tested with $50 \mathrm{~nm}$ particles.

\section{Characterization of LNCs and LNES}

Size distributions and zeta $(\zeta)$ potentials were determined using a Zetasizer ZS (Malvern, Worcestershire, United Kingdom). Particle sizing was based on photon correlation spectroscopy (PCS); the results were analyzed by the CONTIN algorithm, and the sizes were presented based on the volume distributions and the polydispersity indices (PDI). PDI is a dimensionless value that represents the width of the particle size distribution. Electrophoretic mobilities were converted to $\zeta$-potentials using Smoluchowski's equation.

\section{Complement activation evaluation}

Complement consumption was assessed in normal human serum (Etablissement Francais du Sang, Angers, France). The residual haemolytic capacity of the complement system was measured after contact with LNCs or LNEs. Poly(methyl methacrylate) (PMMA) nanoparticles, strong complement activators, ${ }^{23}$ were used as a positive control. This technique determines the amount of serum needed to lyse $50 \%$ of a fixed number of sheep erythrocytes (CH50) that were previously sensitized by rabbit anti-sheep erythrocyte antibodies, as described elsewhere. ${ }^{24}$ Complement activation was expressed as a function of the LNC/LNE surface area, in order to compare particles of different diameters. Nanoparticle surface areas were calculated using the following equations: $S=n 4 \pi r^{2}$ and $V=n(4 / 3)$ $\left(\pi r^{3}\right)$, leading to $S=3 \mathrm{~m} / r \rho$, where $S$ was the surface area $\left(\mathrm{cm}^{2}\right)$ and $V$ was the volume $\left(\mathrm{cm}^{3}\right)$ of $n$ spherical particles of average radius $r(\mathrm{~cm}), m$ was the weight $(\mu \mathrm{g})$ and $\rho$ was the volumetric mass $\left(\mu \mathrm{g} / \mathrm{cm}^{3}\right){ }^{23}$ All experiments were performed in triplicate.

\section{Uptake by THP-1 and HEK293(B3) cells}

THP-1 cells (human monocyte/macrophage cell line, ATCC, Manassas, VA, USA) were grown in suspension in a humidifierincubator $\left(5 \% \mathrm{CO}_{2}\right)$ at $37{ }^{\circ} \mathrm{C}$, in RPMI 1640 supplemented with $10 \%$ fetal bovine serum (FBS), $10 \mathrm{mM}$ HEPES, $1 \mathrm{mM}$ sodium pyruvate, $1.5 \mathrm{~g} / \mathrm{L}$ bicarbonate (Lonza, Verviers, Belgium), $0.05 \mathrm{mM}$ 2-mercaptoethanol, and $100 \mathrm{U} / \mathrm{mL}$ penicillin $\mathrm{G}$ and $100 \mu \mathrm{g} / \mathrm{mL}$ streptomycin (Sigma, Saint-Quentin Fallavier, France). Cells were harvested and counted using the Trypan blue exclusion assay. Approximately $5 \times 10^{5}$ cells $/ 500 \mu \mathrm{L}$ were seeded in sterile 24 -well cell culture dishes and differentiated ${ }^{25}$ by culturing in the same medium with $100 \mathrm{mM}$ Phorbol 12myristate 13-acetate (PMA, Sigma, Saint-Quentin Fallavier, France) for $48 \mathrm{~h}$. Before the experiments the medium was replaced with a PMA-free medium. HEK293(ß3) cells, a human embryonic kidney cell line stably transfected with the human $\beta 3$ integrin gene (kindly provided by J-F. Gourvest, Aventis, France), were cultured as described in ${ }^{26}$ in DMEM supplemented with $1 \%$ glutamine, $10 \%$ FBS and $700 \mu \mathrm{g} / \mathrm{mL}$ Geneticin (G418 sulfate, Gibco, Paisley, United Kingdom). Both types of cells were incubated with DiD-labelled LNCs and LNEs with the same fluorescence intensity. After $15 \mathrm{~min}$ or $1.5 \mathrm{~h}$ incubation at $37^{\circ} \mathrm{C}$, the cells were washed, trypsinized and analyzed by FACS (LSRII, Becton Dickinson, San Jose, USA). The results are presented as DiD histogram counts. Experiments were performed in triplicate.

\section{In vivo distribution}

Female NMRI nude mice (6-8 weeks old, Janvier, Le GenestSaint-Isle, France) were injected subcutaneously with $10 \times 10^{6}$ HEK293(ß3) cells/mouse ( $n=6 /$ group). After tumor growth (6 weeks), anesthetized mice (isoflurane/oxygen 3.5\%-4\% for induction and $1.5 \%-2 \%$ thereafter, CSP, Cournon, France) were injected in the tail vein with $200 \mu \mathrm{L}$ of DiD-containing particles 


\begin{tabular}{lllll}
\hline Nanocarrier type & PEG chain length (Da) & Diameter (nm) & PDI & $\zeta$-Potential (mV) \\
\hline LNC 25 & 660 & $24 \pm 2$ & 0.07 & $-2 \pm 2$ \\
LNC 50 & 660 & $50 \pm 1$ & 0.03 & $-3 \pm 1$ \\
LNC 100 & 660 & $102 \pm 1$ & 0.05 & $-4 \pm 1$ \\
LNC 50 & 1500 & $44 \pm 2$ & 0.16 & $-4 \pm 1$ \\
LNE 25 & 1980 & $26 \pm 1$ & 0.17 & $-11 \pm 1$ \\
LNE 50 & 1980 & $50 \pm 1$ & 0.19 & $-7 \pm 2$ \\
LNE 100 & 1980 & $87 \pm 2$ & 0.25 & $-6 \pm 2$ \\
LNE 50 & 880 & $43 \pm 1$ & 0.15 & $-10 \pm 2$ \\
\hline
\end{tabular}

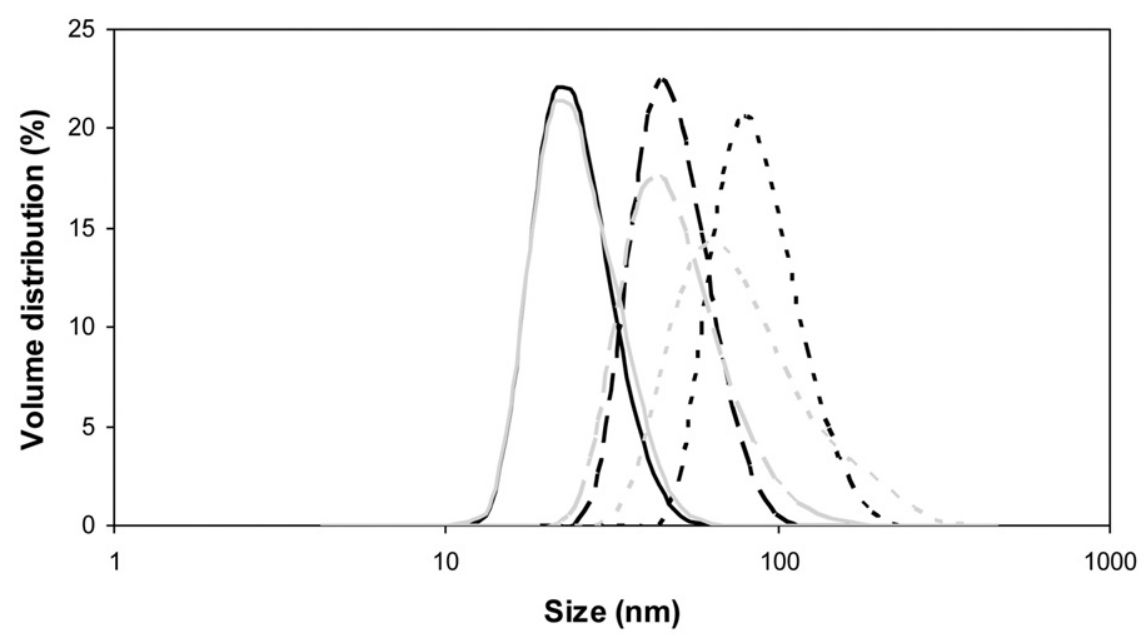

— LNC $20 \mathrm{~nm}$ - - LNC $50 \mathrm{~nm}$ - - - LNC $100 \mathrm{~nm} \longrightarrow$ LNE $20 \mathrm{~nm}$ - - LNE $50 \mathrm{~nm}$ - - - LNC $100 \mathrm{~nm}$

Figure 2. Physico-chemical parameters. LNCs and LNEs differ from the length of the PEG chains covering their surface. The diameters, Polydispersity index and $\zeta$ potentials of the nanocarriers (above), and size distributions of the nanocarriers prepared with PEG 660 Da (LNC) or PEG 1980 Da (LNE) (below) are presented.

suspension. Fluorescent images were acquired by a back-thinned CCD camera at $-80^{\circ} \mathrm{C}$ (ORCAII-BT-512 G, Hamamatsu, Massy, France), $1.5 \mathrm{~h}, 3 \mathrm{~h}, 5 \mathrm{~h}$ and $24 \mathrm{~h}$ after injection. Three mice/group were sacrificed at $5 \mathrm{~h}$ and $24 \mathrm{~h}$ in order to image the organs and analyze the plasma. Image display and analysis were performed using the Wasabi software (Hamamastsu, Massy, France). Semiquantitative data were obtained by drawing regions of interest (ROI) around each organ. All procedures and experimental protocols were approved by the ethical committee of Grenoble for the use of animal research.

The amount of injected particles was standardized and equalized according to their intensity of fluorescence. Additionally, injected concentrations of nanocarriers were adjusted in order to allow comparison with the complement activation test (mg of nanocarrier/mL serum; further converted to surface area of nanocarrier $/ \mathrm{mL}$ serum). The total mouse blood volume was found to be $72 \mathrm{~mL} / \mathrm{kg}$ and contained $55 \%$ serum. The injected nanocarrier concentrations were between 13 and $20 \mathrm{mg} / \mathrm{mL}$, depending on the formulation, resulting in approximately $2.5-$ $3.7 \mathrm{mg} / \mathrm{mL}$ serum in vivo. The studied range in the complement activation test was $0-6.25 \mathrm{mg} / \mathrm{mL}$ serum.

The ability of $50 \mathrm{~nm}$ LNCs and LNEs to accumulate into tumors was also tested. Four groups with 3 mice/group were given subcutaneous tumors. We used human liver cancer (HUH$7,5 \times 10^{6}$ implanted cells), HEK293(ß3) $\left(5 \times 10^{6}\right.$ implanted cells), human glioblastoma (U87MG, $5 \times 10^{6}$ implanted cells), and murine breast cancer (TSA/pc, $10 \times 10^{6}$ implanted cells).

Confocal microscopy of frozen sections $(7 \mu \mathrm{m})$ was carried out on an LSM710 LNO confocal microscope (Carl Zeiss, Jena, Germany) using a $40 \times$ oil immersion objective of 1.0 N.A. The $633-n m$ laser was set up at $3 \%$ of its maximum intensity. Nuclei were labeled by $1 \mu \mathrm{g} / \mathrm{mL}$ of Hoechst 33342 in PBS for 5 min RT.

\section{Results}

\section{Preparation of LNCs and LNES}

The size distributions of the different formulations were homogeneous (Figure 2). LNCs were highly uniform (Polydispersity Indices (PDIs) less than 0.1 ), while LNEs had slightly higher PDIs $(0.1-0.2)$. The $\zeta$-potential for both nanocarriers was weakly negative. Consistent with previous studies, ${ }^{2,5}$ the formulations were stable for several months, except for the $50 \mathrm{~nm}$ LNCs with PEG 1500 chains, for which a temperaturedependent size increase was observed after one month of storage (1.9-fold (at $4{ }^{\circ} \mathrm{C}$ ) and 2.6-fold (at $37^{\circ} \mathrm{C}$ )).

Figure 3. Complement consumption $\left(37^{\circ} \mathrm{C}\right.$ ) of the nanocarriers. (A) The effect of particle's size with LNCs (black) or LNEs (grey) on the complement consumption is presented as a function of the area of particles. We also positioned several flags ('c' for LNCs and ' $e$ ' for LNEs), which correspond to the amount of particles injected in mice in the rest of the study. (B) Effect of modification of the PEG length on the surface. LNCs with "short" PEGs of 660 Da or longer ones (1500 Da), as well as LNEs with short PEGs of $880 \mathrm{Da}$ versus $1980 \mathrm{Da}$ are studied. 


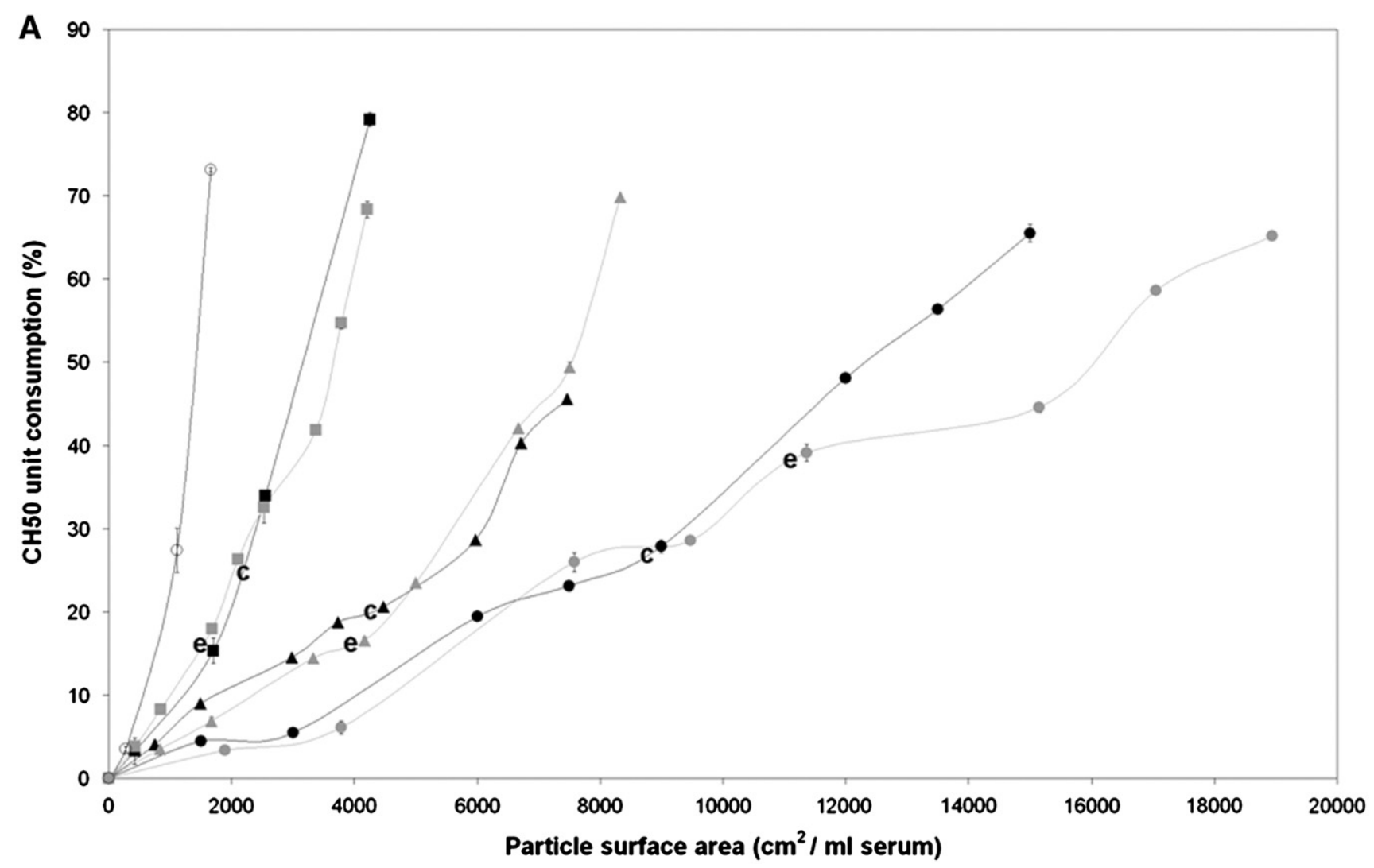

- LNC $25 \mathrm{~nm}-\operatorname{LNC} 50 \mathrm{~nm}-\operatorname{LNC} 100 \mathrm{~nm}-\operatorname{LNE} 25 \mathrm{~nm}-$ LNE $50 \mathrm{~nm}-$ LNE $100 \mathrm{~nm} \bullet$ PMMA

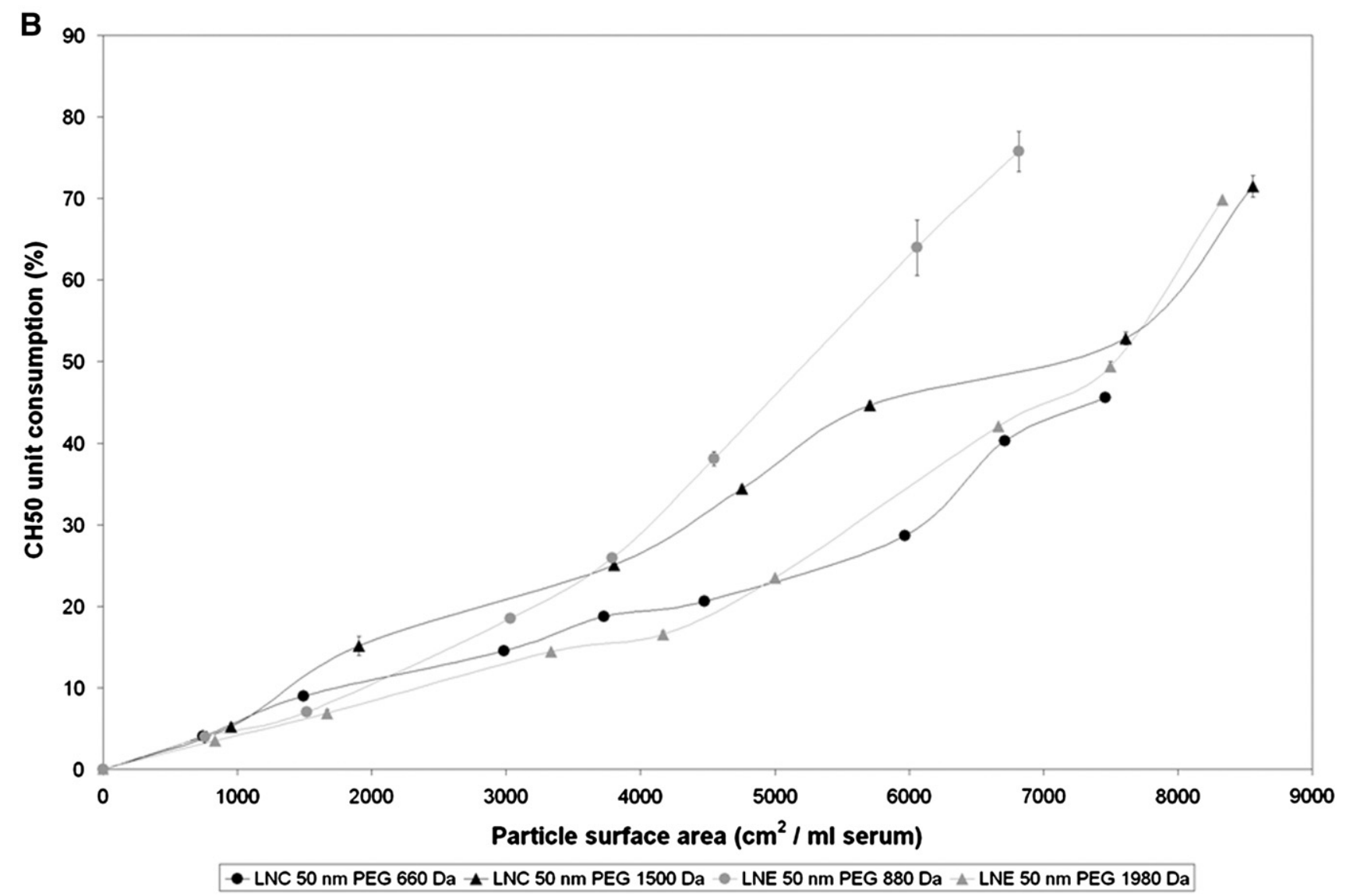




\section{Complement activation}

Complement consumption was evaluated based on the lytic capacity of the serum on $50 \%$ of antibody-sensitized sheep erythrocytes (CH50 units) after exposure to LNCs and LNEs (Figure 3). PMMA nanoparticles of $\pm 150 \mathrm{~nm}$, were used as positive, highly complement-activating controls. Indeed, they consumed $73 \%$ of the $\mathrm{CH} 50$ units when used at a concentration equivalent to a membrane surface of $1673 \mathrm{~cm}^{2} / \mathrm{mL}$. LNCs and LNEs only mildly activated the complement compared to PMMA and no major differences were seen between them: e.g., at $1700 \mathrm{~cm}^{2} / \mathrm{mL}, \mathrm{CH} 50$ consumptions were approximately $5 \%, 9 \%$ and $17 \%$ for 25,50 and $100 \mathrm{~nm}$ particles, respectively. A clear correlation existed between the diameter of the particle and the amount of complement activation: increasing particle size from 25 to $100 \mathrm{~nm}$ increased complement activation. The CH50 unit consumption profiles were modified by exchanging the shorter PEG chain (660 or 880) for a longer one (1500 or 1980), while keeping the particle diameter constant $(50 \mathrm{~nm})$. A long PEG on the LNE surface lowered the CH50 unit consumption, while a short PEG caused the LNCs to have lower complement activation. Because the longer PEG did not benefit LNCs and rendered them unstable, the $50 \mathrm{~nm}$ LNCs with PEG 1500 were not included in subsequent tests. Similarly, because LNEs benefited from the longer PEG chain (1980 Da), LNEs with the shorter PEG chain (880 Da) were excluded from further in vitro tests. Encapsulation of fluorescent dyes in the LNCs and LNEs did not affect the complement activation profiles (data not shown).

\section{Particle uptake by THP-1 macrophages and HEK293(ß3) cells}

Stealth particles are not expected to bind and to be internalized rapidly by cells. This was investigated in vitro by flow cytometry on THP-1 macrophages and HEK293(ß3) cells at $37{ }^{\circ} \mathrm{C}$ (Figure 4). All of the tested nanocarriers showed a barely detectable internalization by THP-1 (Figure 4, A). Only $100 \mathrm{~nm}$ LNCs were slightly more internalized at $1.5 \mathrm{~h}$, but the intensities of fluorescence remained under the cut-off value (vertical lane), indicating weak staining. Similar results were obtained with the HEK293( $\beta 3$ ) cells (Figure 4, B). In this case, $100 \mathrm{~nm}$ LNCs, as well as 50 and $100 \mathrm{~nm}$ LNEs, showed a very weak internalization.

\section{In vivo distribution}

LNCs of 25, 50 and $100 \mathrm{~nm}$ were homogeneously distributed and remained in the circulation for $24 \mathrm{~h}$ after intravenous injection (Figure 5, A). Liver accumulation was weak (regardless of the particle size), while elevated levels of fluorescence were detected in lymph nodes (left cervical lymph node). Plasma fluorescence measurements indicated significant quantities of circulating LNCs. Macroscopically, tumor accumulation was weak in the HEK293( 33 ) model, but the staining intensity of the cervical lymph node (LN) was similar to that observed in the liver. Importantly, this LN is not located on the tumor-bearing side of the mouse, which suggests that the particle accumulation in this LN was not due to tumor drainage. In addition, similar results were observed in nude mice without tumors, suggesting that the LN tropism of these LNCs is not related to tumormediated activation of the LN. Histologic analysis of these lymph nodes demonstrated that most of the signal was located in the trabeculae and paracortex of the lymph nodes, without major observable differences between the different particles (data not shown).

The biodistribution patterns differed when the experiments were performed with 25 to $100 \mathrm{~nm}$ LNEs (Figure 5, B). The skin staining and hepato-biliary evacuation were more pronounced with the smallest LNEs. Liver uptake of the LNEs was low and not affected by LNE's size, while the lymph nodes showed positive labeling. Apart from this difference, the 50 and $100 \mathrm{~nm}$ LNEs performed similarly to the LNCs. Lastly, replacing PEG1800 by PEG900 did not modify the biodistribution. But the fluorescent signal was weaker even though the quantities of injected fluorescence were similar.

\section{Tumor accumulation}

As presented in Figure 5, tumor accumulation of LNCs and LNEs did not differ significantly when evaluated in the HEK293( $\beta 3$ ) model. This was verified on tumor sections and confocal microscopy (Figure 6). The fluorescent signal was always observed, in particular in the periphery of the tumors. The staining was enriched in and around tumor blood vessels but also within the tumor nodules themselves. According to their proximity with the nuclei, fluorescent inclusions were observed in the cytoplasm of tumor and stromal cells as well as in the interstitium space. No major differences are observed between LNEs and LNCs or between 25, 50 or $100 \mathrm{~nm}$ large emulsions.

To evaluate the effect of tumor type on particle accumulation, one nanocarrier size $(50 \mathrm{~nm})$ was tested on different tumors. Accumulation of particles in the tumors was similar, regardless of the nanocarrier type (LNC/LNE). Instead, the accumulation significantly differed between tumor types, while exhibiting consistent organ distribution profiles (Figure 7). Similar to HEK293(ß3),HUH-7 tumors presented poor particle accumulation (poor EPR effect). In comparison, both U87MG and TSA/pc tumors showed strong particle accumulation.

\section{Discussion}

LNCs were prepared by spontaneous formation of emulsion droplets driven by a temperature change, whereas LNEs were formed from a homogenization process by a high-energy source (sonication). Because of the spontaneous formation of LNCs, the quantity of the PEG-surfactant plays a more important role in the LNC fabrication process than in the LNE formulations. Indeed, the amount of Solutol decreased from $69 \%$ to $28 \%$ (of the overall content) as the LNC particle size increased from 25 to $100 \mathrm{~nm}$, while the amount of Myrj 53 decreased from $58 \%$ to $34 \%$ in LNEs (see supplementary Table 1). Spontaneous particle formation without a homogenization step resulted in narrower size distributions (lower PDIs) (Figure 2), as previously observed for polymeric nanoparticles formed either spontaneously (nanoprecipitation) or after homogenization (emulsification techniques). ${ }^{27}$ Particle size selection $(25,50$ and $100 \mathrm{~nm}$ ) for this study was decided according to two factors: we wanted 
A
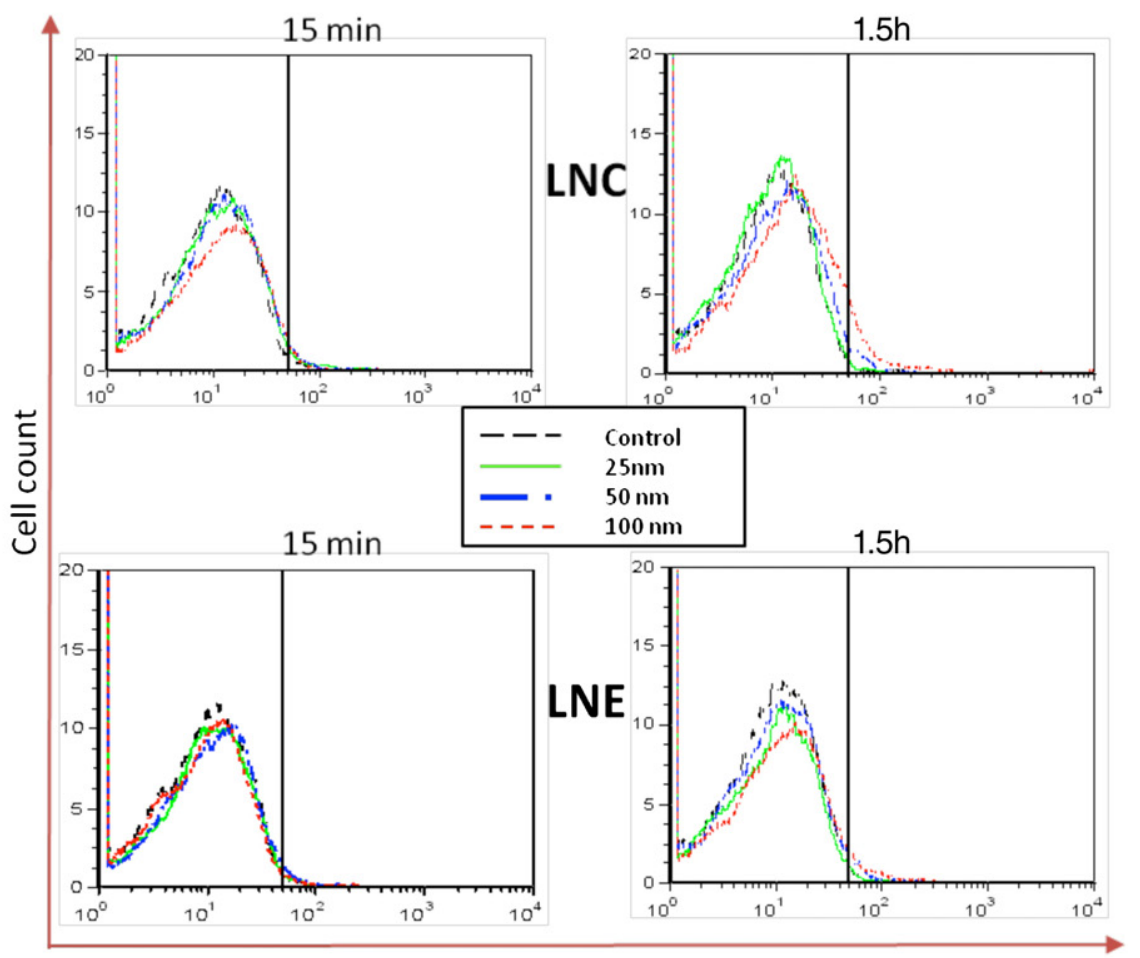

Fluorescence intensity

B

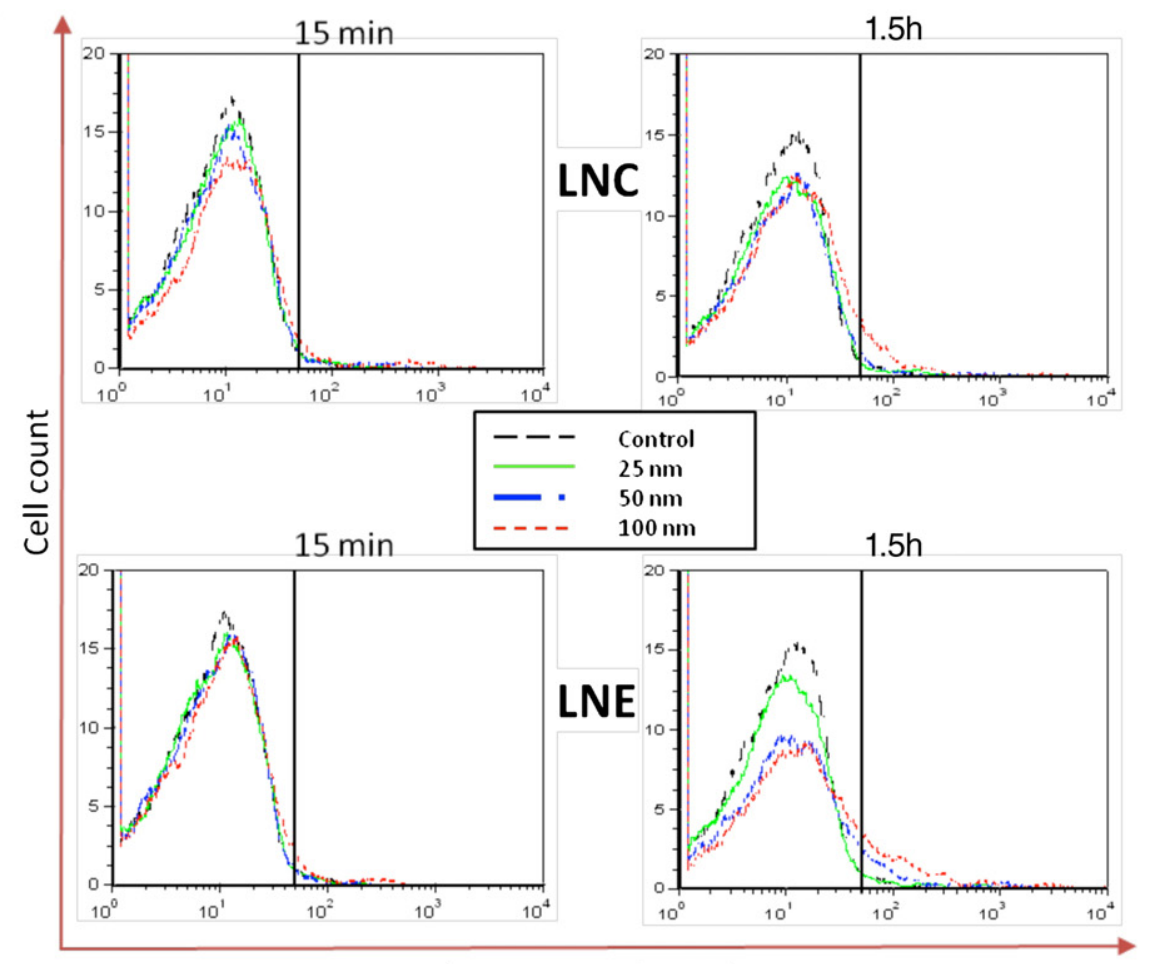

Fluorescence intensity

Figure 4. In vitro uptake by THP-1 macrophages (A) and HEK293 $\left(\beta_{3}\right)$ cells $\mathbf{( B )}$, after $15 \mathrm{~min}$ and $1.5 \mathrm{~h}$ of incubation at $37^{\circ} \mathrm{C}([\mathrm{DiD}]=0.2 \mu \mathrm{M})$. The vertical lane represents the positive cut-off value. All particles tested are poorly internalized by macrophages and HEK293( $\left.\beta_{3}\right)$ cells in vitro, even after $1.5 \mathrm{~h}$ of incubation at $37^{\circ} \mathrm{C}$, indicating that they are really "stealth". 

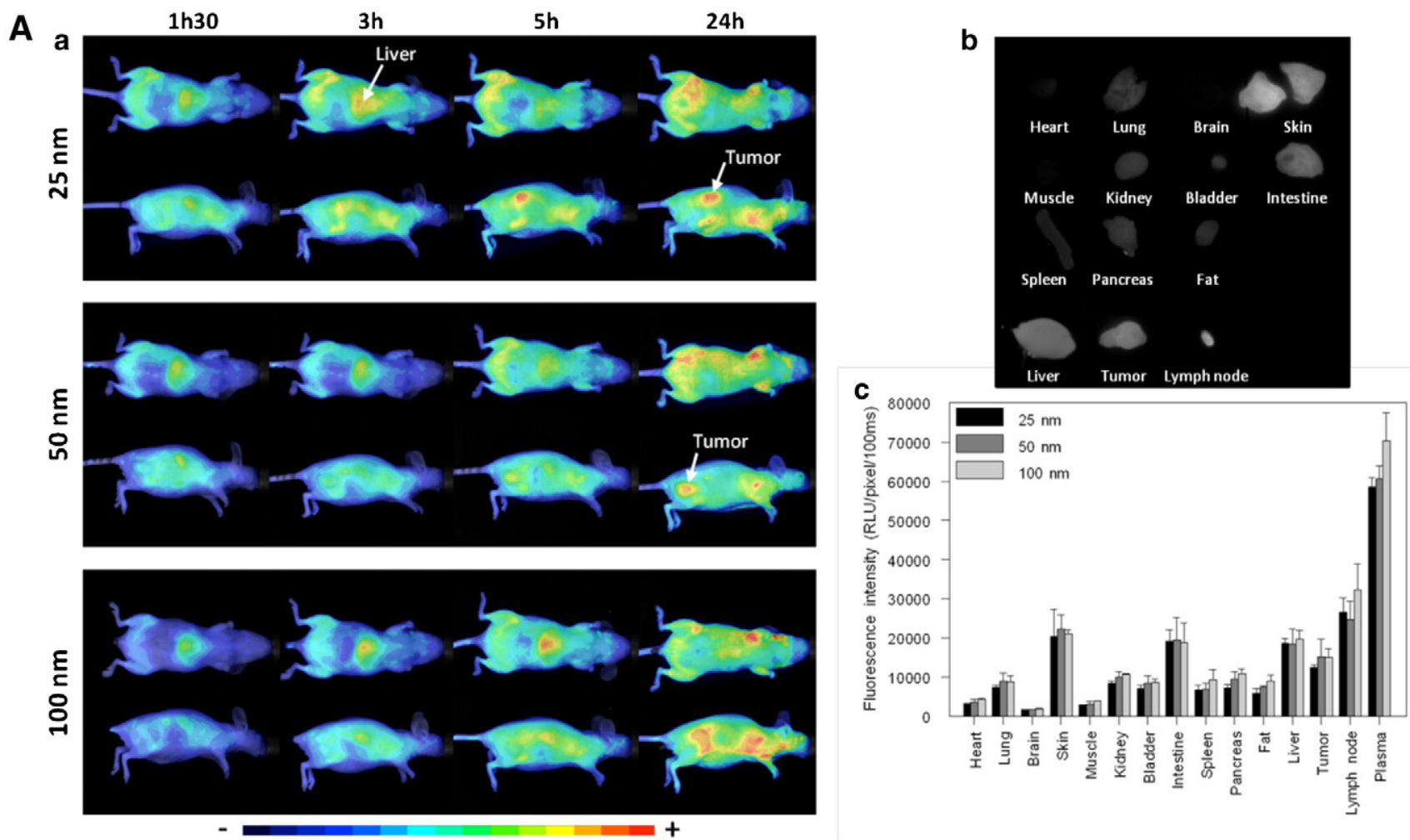

$24 h$
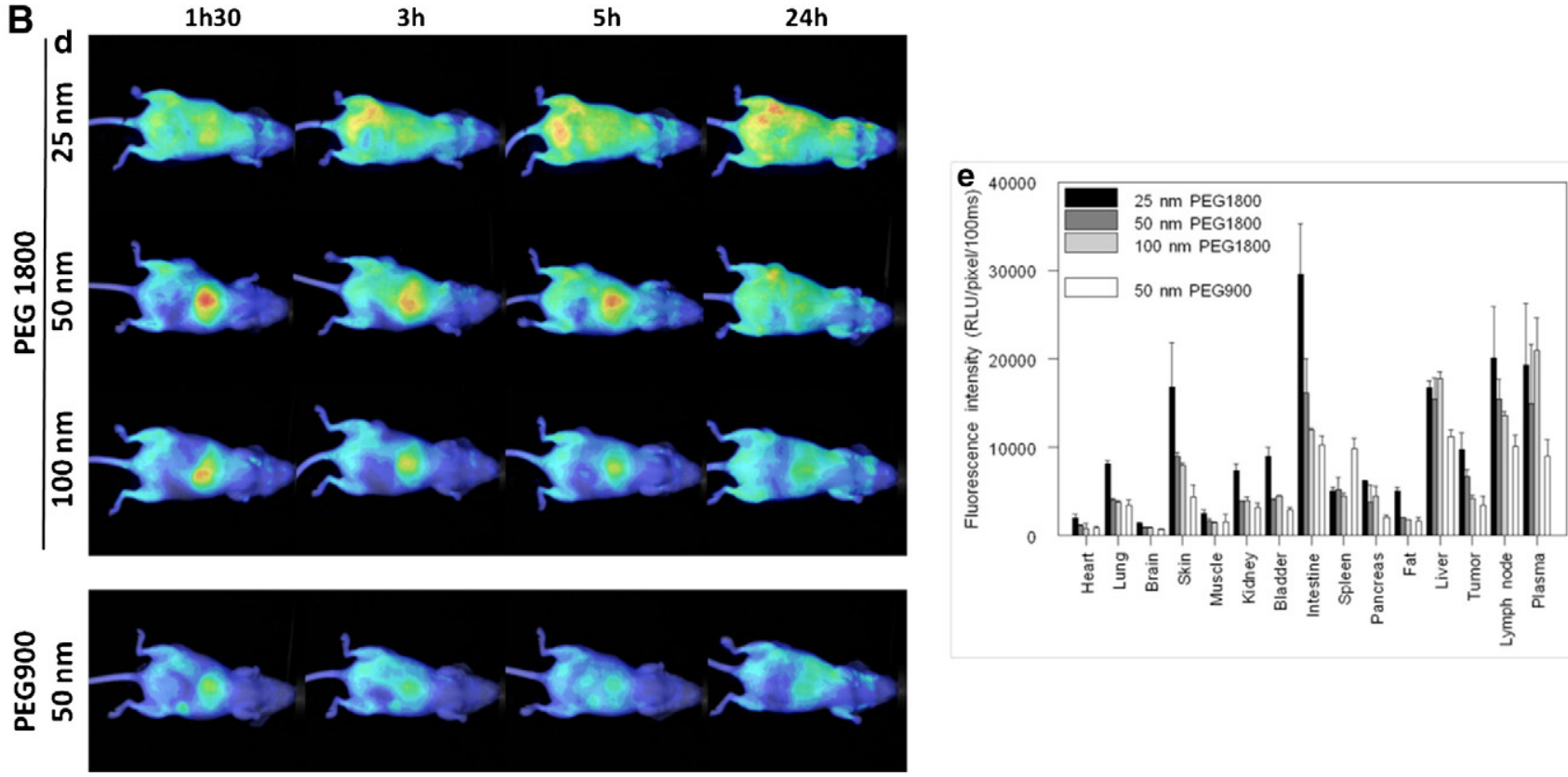

Figure 5. In vivo biodistribution of LNC (A) and LNE (B) in HEK293(ß3) xenografted nude mice. Three sizes of LNCs and LNEs and two sizes of PEGs for LNE $50 \mathrm{~nm}$ were studied. Fluorescence images ( $200 \mathrm{~ms}$ integration time) are recorded at different times after injection and superimposed to visible light images (white and black) (a and d). Fluorescence images are then performed on isolated organs $24 \mathrm{~h}$ after injection (an example of organs extracted from a mouse treated with LNC $50 \mathrm{~nm}$ is presented in (b)). ROIs are then defined on the extracted organs in order to semi-quantify the amount of photons detected per pixels after a $100 \mathrm{~ms}$ exposure. The results of these measurements in each organ and in the plasma are presented in (c) for LNCs and in (e) for LNEs.

to test the extremities of the available size range $(25,100 \mathrm{~nm})$ together with an intermediate size $(50 \mathrm{~nm})$, and on the other hand, studies made with a phase diagram of LNCs provided the narrowest size distributions for these three sizes. ${ }^{3}$ The PEG chains on the surface created a nearly neutral charge, while stabilizing the particles by steric repulsion. The observed slightly negative $\zeta$-potentials could be explained by the presence of a small proportion of hydrolyzed surfactants, leading to a few 


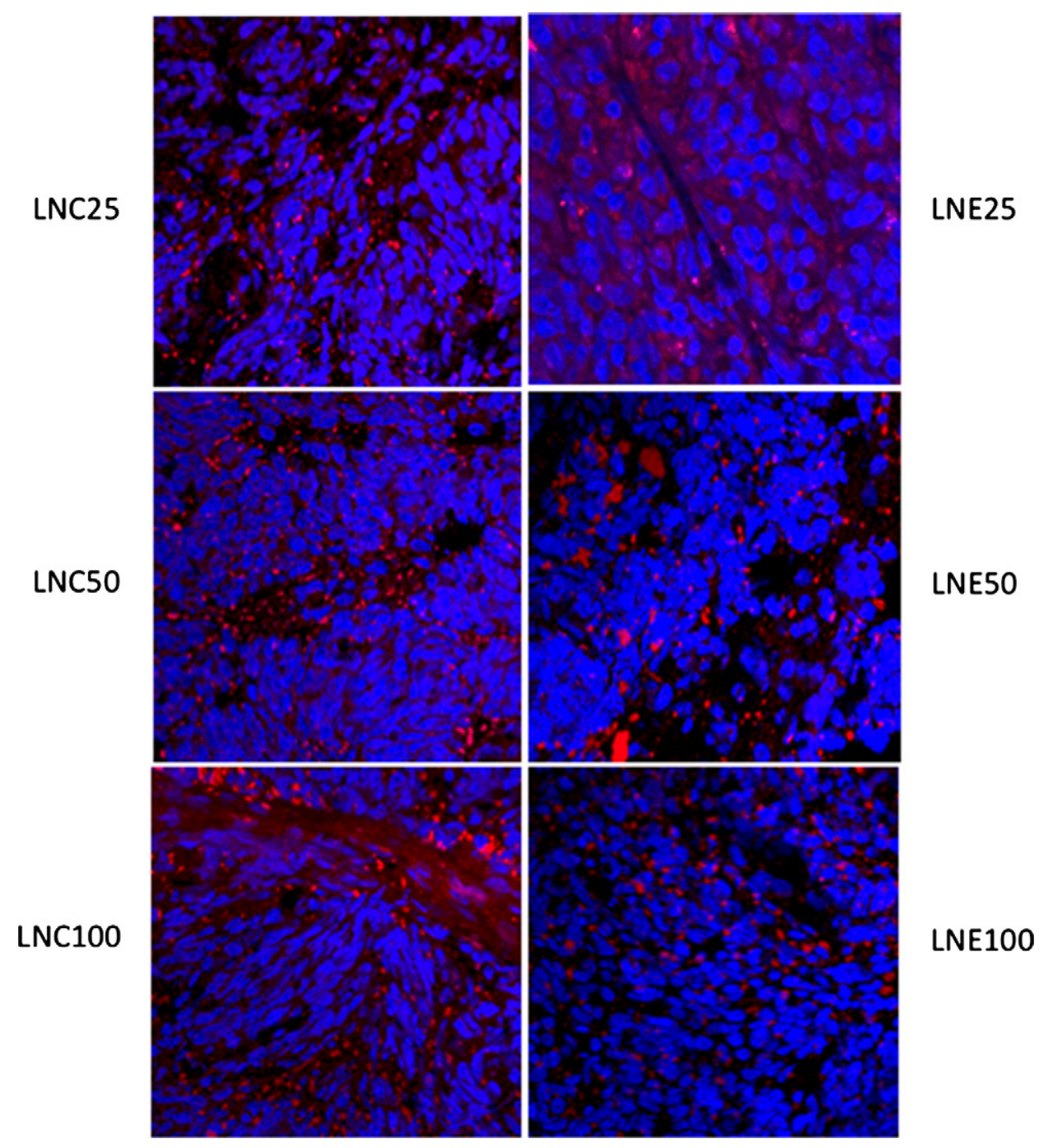

Figure 6. Subcutaneous HEK293(ß3) tumors were extracted and cryo-sectioned before confocal microscopy observation. In blue: Hoechst staining of the nuclei. In red: DiD signal. No major differences can be detected in the distribution and intensity of the different nanoparticles within the tumor.

negatively charged polar groups. ${ }^{28}$ Considering the theoretical calculations of particle quantities (see Materials and Methods), and that all of the PEG surfactants introduced were incorporated into particles, the PEG densities $\left(\mathrm{mol} / \mathrm{m}^{2}\right)$ were lower on the LNE surface as compared to the LNCs, regardless of size (Supplementary Figure 1). This difference in surfactant densities is compensated for by the difference in PEG chain length (LNC: $660 \mathrm{Da}$, LNE: $1980 \mathrm{Da}$ ), providing one major difference between LNCs and LNEs.

In their "standard" formulations, LNCs are prepared with Solutol (PEG $600 \mathrm{Da}$ ), while LNEs are made with Myrj 53 (PEG $1980 \mathrm{Da}$ ) to provide satisfying pharmacokinetics. ${ }^{2,19}$ In this study, LNEs were also prepared with shorter PEG chains $(880 \mathrm{Da})$, while an increased PEG length $(1500 \mathrm{Da})$ was explored in LNC formulations. However, the LNCs with SPEG 1500 were not stable. For the longer PEG chains, no phase inversion zone (from w/o to $\mathrm{o} / \mathrm{w}$ ) was observed; instead, a transition from an $\mathrm{o} / \mathrm{w}$ emulsion to a multiple w/o/ $\mathrm{w}$ emulsion was seen. ${ }^{29}$ This formation mechanism left a remarkable amount of PEG stearate 1500 micelles that did not participate in LNC formation in the dispersion medium. During storage, these structures dissolved and adsorbed on the LNC surface, causing a size increase. Removal of the excess PEG 1500 surfactant was not possible: dialysis could not eliminate the excess material, and other methods such as size exclusion chromatography, led to particle destruction (not shown). Longer PEG chains could be attached to the LNC surface, but this step would require a post-modification procedure. ${ }^{13}$ In comparison, LNEs could use a wider variety of PEG surfactants. This versatility comes from the fact that they are not self-assembled emulsions but require energy input (sonication) to process them and achieve their non-thermodynamically (but long-term kinetically) stable state. ${ }^{6}$

Macrophages can remove nanoparticles from the bloodstream after intravenous administration. ${ }^{30}$ They do not directly identify the nanoparticles, but recognize specific opsonin proteins, such as complement proteins, adsorbed on their surface. ${ }^{31}$ The complement activation test was used to assess the capacity of 
A

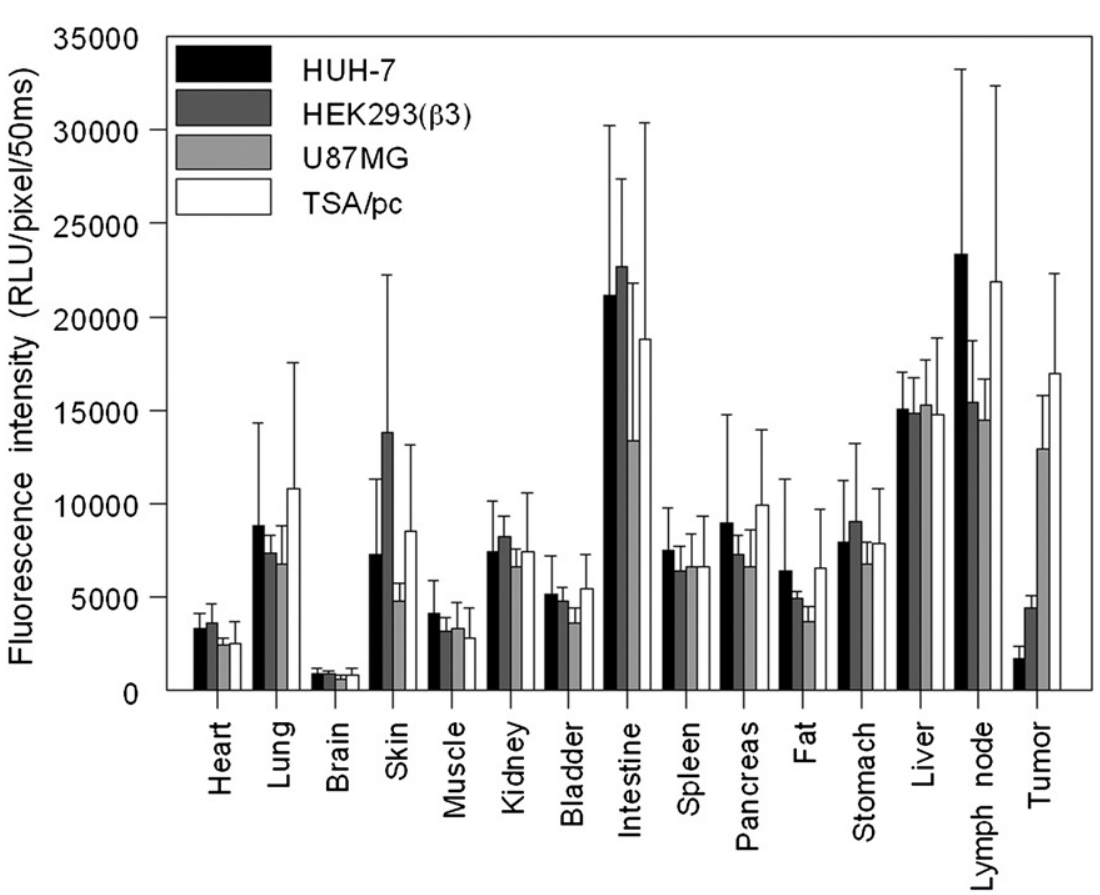

B

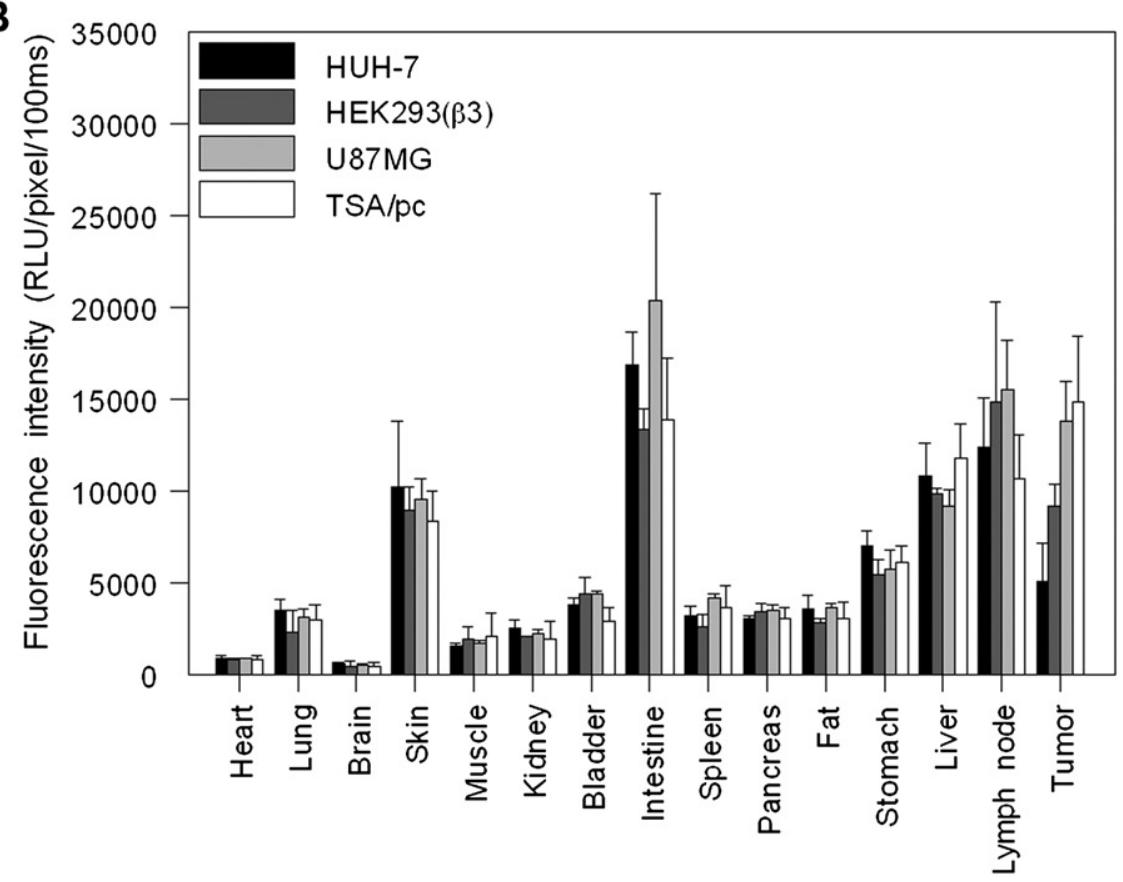

Figure 7. In vivo biodistribution of LNC $50 \mathrm{~nm}(\mathbf{A})$ and LNE $50 \mathrm{~nm}$ (B) in nude mice and evaluation of the EPR effect of the different tumors, $24 \mathrm{~h}$ after injection. Human liver cancer (HUH-7), human glioblastoma (U87MG), human embryonic kidney cells HEK293( $\beta 3$ ) and murine breast cancer (TSA/pc).

the LNCs and LNEs to inhibit the adsorption of complement proteins on their surface. LNCs and LNEs weakly activated the complement system because their high-density PEGylated surface provided a good shield. ${ }^{20}$ The longer PEG chains provided the LNEs with better protection against complement protein adsorption, but the longer PEG (SPEG 1500) caused higher CH50 unit consumption for the LNCs, which resulted from the instability (increased size) of these nanocapsules. Relatively higher amounts of lecithin (Lipoid) on the LNEs' surface structure (Supplementary Figure 1) did not seem to provoke higher protein adsorption compared to LNCs.

Higher complement activation, associated with larger particle size, could be related to the reduced surface curvature of bigger particles that reduces the spatial mobility of the PEG chains (there is more space for the extremities of the PEG to move in the case of smaller particles) and thus facilitates complement adsorption. ${ }^{24}$ It should be noted that the interfacial density of PEGylated surfactant is almost the same, regardless the particle 
size (Supplementary Figure 1), and does not affect complement activation even though the proportion of PEG is higher in the smaller particles.

In vivo experiments were designed to have comparable parameters to evaluate the size, PEG chain length, and nanocarrier (LNE or LNC) effects on particle biodistribution. Particle concentrations were adjusted based on their fluorophore payload, which is a function of the particle volume. One particle of $100 \mathrm{~nm}$ has a surface area of $120,000 \mathrm{~nm}^{2}$. Accordingly, 8 particles of $50 \mathrm{~nm}$ or 125 particles of $25 \mathrm{~nm}$ should be injected to obtain similar quantities of fluorophore, corresponding to $8 \times 30,000=240,000 \mathrm{~nm}^{2}$ or $125 \times 5000=625,000 \mathrm{~nm}^{2}$ of a particle's surface, respectively. Plotting the in vivo nanocarrier concentrations in the complement activation graph (Figure 3, A) showed that all particles consumed between $15 \%$ and $25 \%$ of the available CH50 units, except for the $25 \mathrm{~nm}$ LNEs, which consumed nearly $40 \%$ of the available CH50 units. The differences in the exact particle sizes and injected amounts explained this observed difference: the "25 nm" LNEs had diameters of $22 \mathrm{~nm}$ and $20 \mathrm{mg} / \mathrm{mL}$ concentration, while the " $25 \mathrm{~nm}$ " LNCs had diameters of $28 \mathrm{~nm}$ and a concentration of $19.0 \mathrm{mg} / \mathrm{mL}$. The difference might seem negligible but when it was converted to particle amount (see Materials and Methods), the difference was about $3.8 \times 10^{14}$ particles. In the case of 50 and $100 \mathrm{~nm}$ nanocarriers, the differences between the in vivo injected LNCs and LNEs were less than $1 \times 10^{12}$ particles. Thus, the difference in surface area available for protein adsorption was greater for the $25 \mathrm{~nm}$ LNEs than for the corresponding LNCs. Therefore, for delivering an equal amount of drug payload, the total surface area of the injected particles should only impact complement activation when using the $25 \mathrm{~nm}$ LNEs. No other particles showed surface area-dependent effects on complement activation. The higher drug payload in larger particles counteracts the disadvantage of their surface curvature, which could favor opsonin binding.

No differences of uptake by THP-1 macrophage were observed among the different nanocarriers. In both in vitro and in vivo studies, one goal was to retain the same fluorescence intensity regardless of the nanocarrier size. Because LNCs and LNEs were prepared with the same dye concentration in the oily core $(1.2 \mathrm{mM})$, the particle quantity had to be increased with decreasing particle size, as discussed earlier. A larger quantity of smaller nanocarriers most likely compensated for a possible decrease in the uptake rate of the smaller particles. According to our previous studies, when LNCs $(25-100 \mathrm{~nm})$ were incubated at the same molar concentrations with macrophages, an increased uptake rate was observed with increasing particle size (and increased fluorescence). ${ }^{24}$ Under the same conditions, HEK293(ß3) cells showed similar, negligible uptake of the nanocarriers as seen in THP-1 cells, but as previously established, LNE internalization can be increased by attaching RGD-ligands. ${ }^{7}$

The biodistribution profiles of the nanocarriers presented minor but interesting variations due to their size and/or composition (Figure 5). At early times (1.5 h and $3 \mathrm{~h}$ ), the $25 \mathrm{~nm}$ LNCs and LNEs presented elevated levels of fluorescence in the skin ("green" pseudo color of the animals treated with $25 \mathrm{~nm}$ nanocarriers as compared to the "blue" appearance of those treated with larger nanocarriers). This may be explained by an augmented circulation of small particles in the capillaries of the skin and/or a "burst-release" of the hydrophobic DiD dye, which could be more pronounced with small nanocarriers. The released DiD could be captured by the skin and also evacuated by the hepatobiliary route. A pronounced accumulation of fluorescence with $25 \mathrm{~nm}$ LNEs was measured in the intestine and skin at $24 \mathrm{~h}$, suggesting that, although both types of small particles circulate efficiently in the microcapillaries, the $25 \mathrm{~nm}$ LNEs may be more easily destabilized than LNCs and can release DiD in the skin and circulation.

It is accepted that small-sized nanoparticles have longer circulation times in blood..$^{20,32,33}$ This is usually observed if particles $>100 \mathrm{~nm}$ are compared with particles $<100 \mathrm{~nm}$. However, when nanoparticles with diameters between 10 and $100 \mathrm{~nm}$ are evaluated, the trend is not always obvious. For example, when PEGylated polyacrylate nanoparticles increased from 20 to $60 \mathrm{~nm}$, the systemic clearance rate and liver accumulation decreased significantly. ${ }^{34}$ Similarly, $25 \mathrm{~nm}$ polymer micelles exhibited much shorter circulation half-lives than $60 \mathrm{~nm}$ micelles. ${ }^{35}$ In the latter study, the authors hypothesized that this observation was due to more efficient clearance of the smaller micelles by hepatobiliary excretion because $\sim 70 \%$ of the (mouse) liver fenestrations are narrower than $100 \mathrm{~nm}$. In another study, the longest blood half-life of 10$100 \mathrm{~nm}$ PEGylated gold nanoparticles was achieved by compromising between the particle size and PEG chain length, resulting in $\sim 60 \mathrm{~nm}$ particles. ${ }^{36}$ Our results with the 25 to $100 \mathrm{~nm}$ nanocarriers are consistent with previous studies showing constant (or sometimes even random) distribution profiles in different organs: no clear relationship between the particle size and the biodistribution profiles has been established. ${ }^{34-38}$ Biodistribution results from the current study are compatible with the in vitro complement activation and macrophage uptake evaluations, as no clear differences were observed between the types of nanocarriers. In addition, the PEG-containing surfaces of both LNCs and LNEs provide appropriate stealth properties for the nanocarriers.

Fluorescence imaging only allows the tracking of the (DiD) fluorophore in vivo, which might be different from that of the nanocarriers. However, despite the fact that the in vivo integrity of these lipid nanocarriers cannot be directly confirmed, free DiD dye displays different kinetics and biodistribution than that observed in these studies, and does not fluoresce in aqueous medium. ${ }^{19}$ Therefore, it is assumed that these results reflected the kinetics and biodistribution of the nanocarriers or of the DiD captured locally by tissues.

Tumor vasculature is irregular, leaky, dilated, and the vascular endothelial cells are poorly aligned with large fenestrations. ${ }^{39,40}$ This morphology results in increased leakage of macromolecules and nanocarriers out of the circulatory system into the tumor tissue by the EPR effect. ${ }^{41,42}$ Although Human Embryonic Kidney HEK293 cells form tumors in nude mice, they are not tumor cells but normal embryonic cells transformed with adenovirus 5 DNA. When injected subcutaneously in mice, they form a slow-growing tumor ( $\sim 6$ weeks to reach $5 \mathrm{~mm}),{ }^{43}$ resulting in well-structured, neo-angiogenic vasculature with tight endothelial junctions. ${ }^{26,44}$ Therefore, HEK293( $\beta 3$ ) tumors 
can be classified as "weak EPR" tumors. TSA/pc cells originate from chemically induced tumors in mice. They grow rapidly ( $\sim 10$ days to $5 \mathrm{~mm}$ ), leading to leaky fenestrations. ${ }^{45}$ Additionally, tumors from U87MG cells exhibit highly porous vasculature. ${ }^{46}$ The results from the $50-\mathrm{nm}$ LNCs and LNEs support these conclusions: significantly more nanocarriers were found in the TSA/pc and U87MG tumors, compared to the HEK293(ß3) and HUH7 tumors. In addition, four independent experiments confirmed that the biodistribution of these nanocarriers was highly reproducible and homogenous. The particles stained the skin, liver, LNs and tumors. In summary, LNCs and LNEs showed good stealth properties and can target passively the lymph nodes and EPR "positive" tumors, which is promising for clinical applications.

\section{Appendix A. Supplementary data}

Supplementary data to this article can be found online at http://dx.doi.org/10.1016/j.nano.2012.08.005.

\section{References}

1. Heurtault B, Saulnier P, Benoit JP, Proust JE, Pech B, Joel R. Lipid nanocapsules, preparation method and use as medicine. Edited by 2001, p.

2. Heurtault B, Saulnier P, Pech B, Proust J-E, Benoit J-P. A novel phase inversion-based process for the preparation of lipid nanocarriers. Pharm Res 2002;19:875-80.

3. Heurtault B, Saulnier P, Pech B, Venier-Julienne M-C, Proust J-E, PhanTan-Luu R, et al. The influence of lipid nanocapsule composition on their size distribution. Eur J Pharm Sci 2003;18:55-61.

4. Goutayer M, Texier-Nogues I, Fattaccioli J, Bibette J. Fluorescent emulsions for optical imaging. Edited by 2008, p.

5. Delmas T, Couffin A-C, Bayle PA, Fd Crécy, Neumann E, Vinet F, et al. Preparation and characterization of highly stable lipid nanoparticles with amorphous core of tuneable viscosity. J Colloid Interface Sci 2011.

6. Delmas T, Piraux H, Couffin A-C, Texier I, Vinet F, Poulin P, et al. How to prepare and stabilize very small nanoemulsions. Langmuir 2011;27:1683-92.

7. Goutayer M, Dufort S, Josserand V, Royère A, Heinrich E, Vinet F, et al. Tumor targeting of functionalized lipid nanoparticles: assessment by in vivo fluorescence imaging. Eur J Pharm Biopharm 2010;75:137-47.

8. Peltier S, Oger JM, Lagarce F, Couet W, Benoit JP. Enhanced oral paclitaxel bioavailability after administration of paclitaxel-loaded lipid nanocapsules. Pharm Res 2006;23:1243-50.

9. Lacoeuille F, Hindre F, Moal F, Roux J, Passirani C, Couturier O, et al. In vivo evaluation of lipid nanocapsules as a promising colloidal carrier for paclitaxel. Int J Pharm 2007;344:143-9.

10. Garcion E, Lamprecht A, Heurtault B, Paillard A, Aubert-Pouessel A, Denizot B, et al. A new generation of anticancer, drug-loaded, colloidal vectors reverses multidrug resistance in glioma and reduces tumor progression in rats. Mol Cancer Ther 2006;5:1710-22.

11. Cirpanli Y, Allard E, Passirani C, Bilensoy E, Lemaire L, Calis S, et al. Antitumoral activity of camptothecin-loaded nanoparticles in 9L rat glioma model. Int J Pharm 2011;403:201-6.

12. Lamprecht A, Saumet JL, Roux J, Benoit JP. Lipid nanocarriers as drug delivery system for ibuprofen in pain treatment. Int J Pharm 2004;278: 407-14.

13. Morille M, Montier T, Legras P, Carmoy N, Brodin P, Pitard B, et al. Long-circulating DNA lipid nanocapsules as new vector for passive tumor targeting. Biomaterials 2010;31:321-9.
14. Morille M, Passirani C, Dufort S, Bastiat G, Pitard B, Coll JL, et al. Tumor transfection after systemic injection of DNA lipid nanocapsules. Biomaterials 2011;32:2327-33.

15. Vanpouille-Box C, Lacoeuille F, Belloche C, Lepareur N, Lemaire L, LeJeune JJ, et al. Tumor eradication in rat glioma and bypass of immunosuppressive barriers using internal radiation with (188)Re-lipid nanocapsules. Biomaterials 2011;32:6781-90.

16. Vanpouille-Box C, Lacoeuille F, Roux J, Aube C, Garcion E, Lepareur $\mathrm{N}$, et al. Lipid nanocapsules loaded with rhenium-188 reduce tumor progression in a rat hepatocellular carcinoma model. PLoS One 2011;6: e16926.

17. Allard E, Hindre F, Passirani C, Lemaire L, Lepareur N, Noiret N, et al. 188Re-loaded lipid nanocapsules as a promising radiopharmaceutical carrier for internal radiotherapy of malignant gliomas. Eur J Nucl Med Mol Imaging 2008;35:1838-46.

18. Goutayer M, Dufort S, Josserand V, Royere A, Heinrich E, Vinet F, et al. Tumor targeting of functionalized lipid nanoparticles: assessment by in vivo fluorescence imaging. Eur J Pharm Biopharm 2010;75: 137-47.

19. Texier I, Goutayer M, Da Silva A, Guyon L, Djaker N, Josserand V, et al. Cyanine-loaded lipid nanoparticles for improved in vivo fluorescence imaging. J Biomed Opt 2009;14:054005.

20. Vonarbourg A, Passirani C, Saulnier P, Benoit J-P. Parameters influencing the stealthiness of colloidal drug delivery systems. Biomaterials 2006;27:4356-73.

21. Maeda H, Wu J, Sawa T, Matsumura Y, Hori K. Tumor vascular permeability and the EPR effect in macromolecular therapeutics: a review. J Control Release 2000;65:271-84.

22. Bellis SL. Advantages of RGD peptides for directing cell association with biomaterials. Biomaterials 2011;32:4205-10.

23. Passirani C, Barratt G, Devissaguet J-P, Labarre D. Interactions of nanoparticles bearing heparin or dextran covalently bound to poly(methyl methacrylate) with the complement system. Life Sci 1998;62: 775-85.

24. Vonarbourg A, Passirani C, Saulnier P, Simard P, Leroux J-C, Benoît JP. Evaluation of pegylated lipid nanocapsules versus complement system activation and macrophage uptake. J Biomed Mater Res A 2006;78A: 620-8.

25. Tsuchiya S, Kobayashi Y, Goto Y, Okumura H, Nakae S, Konno T, et al. Induction of maturation in cultured human monocytic leukemia cells by a phorbol diester. Cancer Res 1982;42:1530-6.

26. Jin Z-H, Josserand V, Foillard S, Boturyn D, Dumy P, Favrot M-C, et al. In vivo optical imaging of integrin $\alpha_{\mathrm{v}}-\beta_{3}$ in mice using multivalent or monovalent cRGD targeting vectors. Mol Cancer 2007;6:41.

27. Quintanar-Guerrero D, Allémann E, Fessi H, Doelker E. Preparation techniques and mechanisms of formation of biodegradable nanoparticles from preformed polymers. Drug Dev Ind Pharm 1998;24:1113-28.

28. Ohshima H. Electrokinetics of soft particles. Colloid Polym Sci 2007; 285:1411-21.

29. Béduneau A, Saulnier P, Anton N, Hindré F, Passirani C, Rajerison H, et al. Pegylated nanocapsules produced by an organic solvent-free method: evaluation of their stealth properties. Pharm Res 2006;23:2190-9.

30. Gref R, Minamitake Y, Peracchia MT, Trubetskoy V, Torchilin V, Langer R. Biodegradable long-circulating polymeric nanoparticles. Science 1994;263:1600-3.

31. Frank MM, Fries LF. The role of complement in inflammation and phagocytosis. Immunol Today 1991;12:322-6.

32. Dufort S, Sancey L, Coll JL. Physico-chemical parameters that govern nanoparticles fate also dictate rules for their molecular evolution. $A d v$ Drug Deliv Rev 2011;64:179-89.

33. Lux F, Mignot A, Mowat P, Louis C, Dufort S, Bernhard C, et al. Ultrasmall rigid particles as multimodal probes for medical applications. Angew Chem Int Ed Engl 2011;50:12299-303.

34. Yang Z, Leon J, Martin M, Harder JW, Zhang R, Liang D, et al. Pharmacokinetics and biodistribution of near-infrared fluorescence polymeric nanoparticles. Nanotechnology 2009;20:165101. 
35. Lee H, Fonge H, Hoang B, Reilly RM, Allen C. The effects of particle size and molecular targeting on the intratumoral and subcellular distribution of polymeric nanoparticles. Mol Pharm 2010;7:1195-208.

36. Perrault SD, Walkey C, Jennings T, Fischer HC, Chan WCW. Mediating tumor targeting efficiency of nanoparticles through design. Nano Lett 2009;9:1909-15.

37. Meng H, Xue M, Xia T, Ji Z, Tarn DY, Zink JI, et al. Use of size and a copolymer design feature to improve the biodistribution and the enhanced permeability and retention effect of doxorubicin-loaded mesoporous silica nanoparticles in a murine xenograft tumor model. ACS Nano 2011;5:4131-44.

38. Sun X, Rossin R, Turner JL, Becker ML, Joralemon MJ, Welch MJ, et al. An assessment of the effects of shell cross-linked nanoparticle size, core composition, and surface PEGylation on in vivo biodistribution. Biomacromolecules 2005;6:2541-54.

39. Baban DF, Seymour LW. Control of tumour vascular permeability. Adv Drug Deliv Rev 1998;34:109-19.

40. Konerding MA, Fait E, Gaumann A. 3D microvascular architecture of pre-cancerous lesions and invasive carcinomas of the colon. Br J Cancer 2001;84:1354-62.
41. Matsumura Y, Maeda H. A new concept for macromolecular therapeutics in cancer chemotherapy: mechanism of tumoritropic accumulation of proteins and the antitumor agent Smancs. Cancer Res 1986;46:6387-92.

42. Fang J, Nakamura $H$, Maeda $H$. The EPR effect: unique features of tumor blood vessels for drug delivery, factors involved, and limitations and augmentation of the effect. Adv Drug Deliv Rev 2011;63:136-51.

43. Dufort S, Sancey L, Hurbin A, Foillard S, Boturyn D, Dumy P, et al. Targeted delivery of a proapoptotic peptide to tumors in vivo. J Drug Target 2011;19:582-8.

44. Razkin J, Josserand V, Boturyn D, Z-h Jin, Dumy P, Favrot M, et al. Activatable fluorescent probes for tumour-targeting imaging in live mice. ChemMedChem 2006;1:1069-72.

45. Sancey L, Ardisson V, Riou L, Ahmadi M, Marti-Batlle D, Boturyn D, et al. In vivo imaging of tumour angiogenesis in mice with the $\alpha \mathrm{v} \beta 3$ integrin-targeted tracer ${ }^{99 \mathrm{~m}} \mathrm{Tc}-\mathrm{RAFT}-\mathrm{RGD}$. Eur J Nucl Med Mol Imaging 2007;34:2037-47.

46. Hobbs SK, Monsky WL, Yuan F, Roberts WG, Griffith L, Torchilin VP, et al. Regulation of transport pathways in tumor vessels: role of tumor type and microenvironment. Proc Natl Acad Sci U S A 1998;95:4607-12. 